\title{
Container Production Management System based on the CPS
}

\author{
Lu Haifeng, ${ }^{1}$ Xu Fangqin ${ }^{2}$ \\ ${ }^{1}$ School of Information and Technology, Shanghai Jianqiao University, China \\ ${ }^{2}$ School of Information Science and Technology, East China Normal University, School of Information and Technology, Shanghai \\ Jianqiao University, China \\ luxianglin1993@gmail.com,52101214004@student.ecnu.edu.cn
}

\begin{abstract}
CPS (Cyber Physical System) is a multi-dimensional complex system that synthesizes computing, networking and physical environment, it implements a large engineering system of real-time perception, dynamic control and information service by the organic integration and highly collaborative of $3 \mathrm{C}$ technology. The article mainly designs and plans the architecture of Container Management system, it firstly introduces the concept and characteristics of the CPS, then it outlines the prospects and framework of the CPS in combination with container production management system, and make sure the system research platform. After optimizing the management system, it will make full use of the Internet to achieve the data of real-time, detailed and transparent, so as to provide convenience for the service goal.[1]

Index Terms - CPS, Container Production Management System, development platform
\end{abstract}

\section{The Development Prospects of Container}

Container transport, especially in the Marine transportation has many advantages: one is the large transportation volume. Container transport is advantaged for the mechanized loading and unloading prior to the scattered goods transport in a suitcase, and it greatly shortens the duration of the ships in the harbor and the goods in the warehouse storage time, accelerates the speed of the freight and reduces the transportation cost; Unified box specifications can ship more goods in the same volume loading and increase the transport. The second is to reduce the breakage of the goods. Container handling can ensure goods the intact when the freight transport, almost completely eliminate amount of items loss and greatly reduce the damage and compensation. For example, the damage rate is $15 \%$ when we deliver glass plate as usual, but it is only $0.2 \sim 1 \%$ by the container transportation. The third is to save packing material. The packing material of taking simple packaging and bulk transportation is disposable; But the container is reusable, and can reduce the cost of packing and unpacking, it is good for the customers. All in all, containerization can speed up the transportation, reduce shipping costs and be easy to multimodal combined transport by rail and sea, is an important index of national economic development. Therefore, it is very important to realize the automation and unification of container transportation.[2]

\section{The Concept and Characteristics of CPS}

CPS is a integration system that combines physical process and calculation process, is the human by the CPS system includes digital world and mechanical device to interact with the physical world, the main body of this interaction includes human beings and system that people know. The object that is affected includes the various aspects of the real world: natural environment, buildings, machines, and human beings. CPS is a distributed heterogeneous system, it contains many functions of different subsystems, and these subsystems have different structures and functions, they are distributed in different geographical scope. Every subsystem should coordinate with each other through wired and wireless communication mode.

CPS have adaptability, autonomy, high efficiency, functionality, reliability and security etc, it is an intelligent system that have autonomous behavior.CPS can retrieve data from the environment, and extract the effective information by data fusion, then it can affect the environment by the effector according to the rules of the system. Therefore, the CPS system is used for container production management system, it provides a stable information technology service platform for small and medium container port logistics, and it has great significance for reasonable deployment of resources, energy saving, environmental protection, the benefit of the people's livelihood, etc.[3]

\section{The Organization Framework of System}

The overall structure framework is shown in figure 1, in the process of container management system software development, operation of users will not be restricted from old hardware devices if CPS could be merged to software exploitation, and users can achieve a high level of computing and searching through low configuration of physical hardware. Briefly, if the technique success, we will do anything we want only through a browser machine when the Internet is available, and it removes the huge obstacle of hardware limits.

According to the needs of container management and information service, there are several layers in CPS system as "service layer", "planning layer", "dispatching monitor layer", "manufacture management layer", "statistical analysis layer". Each system consists of many interfaces that have different functions, and each interface needs communication in order to coordinate with each other. 


\begin{tabular}{|c|c|c|c|c|c|c|c|c|}
\hline \multicolumn{9}{|c|}{ Container Production Management System } \\
\hline EDI & \multicolumn{2}{|c|}{$\begin{array}{l}\text { Reservation } \\
\text { System }\end{array}$} & $\begin{array}{l}\text { Inland Feeder } \\
\text { Platform }\end{array}$ & Data Center & \multicolumn{2}{|c|}{ Website } & \multicolumn{2}{|c|}{$\begin{array}{l}\text { Audio Message } \\
\text { Telephone }\end{array}$} \\
\hline \multicolumn{9}{|c|}{ service layer } \\
\hline \multicolumn{2}{|c|}{ Berth Planning } & \multicolumn{2}{|c|}{ Resource Planning } & \multicolumn{2}{|c|}{ Ship Planning } & \multicolumn{3}{|c|}{ Container Yard Plaming } \\
\hline \multicolumn{9}{|c|}{ Planning Layer } \\
\hline Pier Monitoring & \multicolumn{2}{|c|}{ Ship Monitoring } & $\begin{array}{l}\text { Container Yard } \\
\text { Monitoring }\end{array}$ & $\begin{array}{l}\text { Mechanical } \\
\text { Monitoring }\end{array}$ & \multicolumn{2}{|c|}{$\begin{array}{c}\text { Access Hatch } \\
\text { Monitoring }\end{array}$} & & operation \\
\hline \multicolumn{9}{|c|}{ Dispatching Monitor Layer } \\
\hline $\begin{array}{c}\text { System } \\
\text { management }\end{array}$ & $\begin{array}{c}\text { Import and } \\
\text { export } \\
\text { management }\end{array}$ & query & \begin{tabular}{l|c} 
ry & $\begin{array}{c}\text { Project } \\
\text { acceptance }\end{array}$
\end{tabular} & Charge & $\begin{array}{l}\text { Access } \\
\text { Hatch }\end{array}$ & Buffer A & & CFS \\
\hline \multicolumn{9}{|c|}{ Manufacture Management Layer } \\
\hline Ship Operation & \multicolumn{2}{|c|}{$\begin{array}{c}\text { Container Yard } \\
\text { Operation }\end{array}$} & $\begin{array}{c}\text { Human } \\
\text { Resources }\end{array}$ & $\begin{array}{c}\text { Mechanical } \\
\text { Resource }\end{array}$ & \multicolumn{2}{|c|}{$\begin{array}{l}\text { Access Hatch } \\
\text { Operation }\end{array}$} & & operate \\
\hline \multicolumn{9}{|c|}{ Statistical Analysis Layer } \\
\hline
\end{tabular}

Fig 1.System Structure Drawing

\section{A. Service layer}

\section{1) Reservation Interface}

The reservation of extracting container is proposed by customers, then uploading it to the data center, and data center automatically transfers the information to the corresponding shipping company.

\section{2) Website Interface}

Customers can log in designated sites and enter the information of relevant confirmation, then they can check the information of the container in real time, suck as loading/discharging information, container transport information, inspection information, the time of opening/closing door, the location and status of container, etc.

\section{3) Data Center Interface}

Inputting the data of containers, goods and others by electronic tag, then transmitting them to the data center by a wireless LAN or $3 \mathrm{G}$ network. So data center can implement the real-time online monitoring, and customers can query the logistics information in the system website at any time.

\section{B. Planning Layer}

\section{1) Berth Planning Interface}

Data center arranges the ship information by date, including name and voyage of ship, the length of ship, berthing direction (left side or right side), berthing time and so on.

\section{2) Resource Planning Interface}

Data center distributes the resources of the pier according to the information of container and ship, including human resources, equipment resources, material resources and capital resources, and so on.

\section{3) Ship Planning Interface}

Data center arranges suitable ships according to requirements of shippers, it improves the dense of relevant containers and increases the utilization rate of transport machines.

4) Container Yard Planning Interface

Data Center classifies automatically containers, and stores separately them according to destinations that containers will be sent to, it can avoid re-stow, waiting for hoisting and so on.

\section{Dispatching Monitor Layer \\ 1) Pier Monitoring Interface}

Every monitoring equipment of the pier uploads images to the data center, and it can know the whole situation of the pier at any time to achieve all-round monitoring for 24 hours.

\section{2) Ship Monitoring Interface}

Ship realizes the dynamic monitoring of the ship by shipborne satellite. On the one hand, the ship company and shippers can know the safe management of ship. On the other hand, the port administration authority can realize monitoring all ships to facilitate better arrangement plan and to ensure the safety of port. In addition, the shipping service auxiliary industries such as shipping agency company, spare parts material supply company can get more business opportunities by making contact with owners of ships in advance.

\section{3) Container Yard Monitoring Interface}

Data center masters yard of real-time dynamic according to monitoring, and helps the production management personnel know the utilize situation of the yard.

\section{4) Mechanical Monitoring Interface}

Through mechanical monitoring system, data center can know the operation of remote devices and various parameters, to realize remote operation, remote management, remote control, remote fault diagnosis and remote maintenance.

\section{5) Access Hatch Monitoring Interface}

Data center examines information of containers through remote equipments, and uploads information to the data center.

\section{Manufacture Management Layer}

\section{1) Query Interface}

Data center provides the query of relevant information, including monitoring of all equipments, situations of port resource planning, correlative charges of operations, etc.

\section{2) Charging Interface}

Data center unifies data and clears automatically fees of all homeworks, including customer agreement management, basic rate management, charge for confirmation, charging analysis and statistical summary, etc. 


\section{3) Plan Accepted Interface}

Accepting all kinds of plans according to customer requirements. For example, customers apply for taking out containers on the net, and data center accepts online booking of containers.

4) Access Hatch Interface

Data center manages access hatches, and determines whether to allow containers to go through.

\section{E. Statistical Analysis Layer}

\section{1) Ship Operation Interface}

Data center provides throughput statistics of ships over a period of time.

\section{2) Container Yard Operation Interface}

Data center provides throughput statistics of container yard over a period of time.

\section{3) Human Resources Interface}

Data center provides situations of human resource allocation and individual assignment over a period of time.

4) Mechanical Resource Interface

Data center provides mechanical resource usage over a period of time.

\section{5) Access Hatch Operation Interface}

Data center provides work situations of access hatch over a period of time.

To sum up, we can put the CPS abstract for the four aspects of "feel", "connect", "know", "control". "Feel" means perceptrons that cooperate with each other perceive the physical world."Connect" means connecting the information world with the physical world, to realize the data exchange and support collaborative perception and control."Know" means cognizing correctly and deeply the physical world according to perception data."Control" means determining the control strategy and sending control instruction according to the result of cognition, commandding coordinated actuators to control the physical world. Therefore, in order to integrate the CPS system with the container production management system, we have to achieve breakthrough in the four aspects of "feel", "connect", "know", "control".[4]

\section{Development Platform and Database Platform}

The design of the software using Visual studio 2010 development environment and SQL Server 2008 data platform. Compared with other software, they have been widely praised and promoted. The container system software adopts $\mathrm{B} / \mathrm{S}$ architecture, the core of software is located on the Internet, clients can use web browser such as Internet Explorer to view data and exchange data by Web Server. It reduces burthen of Clients' computers, decreasing costs and workload of system upgrade.[5]

\section{Conclusions}

CPS can achieve reasonable allocation of production resources, human resources and economic resources according to the information interaction of each node in the environment. In addition, CPS can achieve operations of monitoring and warning, and it can also achieve emergency processing in emergency circumstances. Therefore, CPS has profound development potential and market demand if it is applied to the container freight.

\section{References}

[1] Dj.M. Maric, P.F. Meier and S.K. Estreicher: Mater. Sci. Forum Vol. 83-87 (1992), p. 119.

[2] Advances in Internet of Things. Scientific Research Publishing Vol.01 No.02, Jul. 2011; Page 32.

[3] Yampolskiy, M.; Horvath, P; Koutsoukos, X.D; Yuan Xue; Sztipanovits, J." Systematic analysis of cyber-attacks on CPS-evaluating applicability of DFD-based approach" Publication Year: 2012, Page(s): $55-62$.

[4] Chen Li-na; Huang Hong-bin; Deng Su." Research on CPS spatio-temporal event model based on the state" Publication Year: 2011, Page(s): 195 - 198.

[5] Yoojin Lim; Eunmi Choi." The CPS with the Hadoop ecosystems" Publication Year: 2013, Page(s): 1 - 4. 